\title{
An Investigation Into the Effects of Prenatal Care Instruction at Home on Breast-Feeding Self-Efficacy of First-Time Pregnant Women Referred to Shiraz Clinics, Iran
}

\author{
Hamideh Mohseni ${ }^{1}$, Iran Jahanbin ${ }^{2 *}$, Eghbal Sekhavati ${ }^{3}$, Reza Tabrizi $^{4}$, Maasoumeh Kaviani ${ }^{2}$, Fariba Ghodsbin ${ }^{2}$
}

\begin{abstract}
Objectives: Mother's milk is very complex biologic liquid for babies. It is strongly recommended that babies be fed exclusively by mother's milk for the first 6 months of baby's life and be continued until she is 2 years old. The mothers' self-efficiency is the main factor to predict the breastfeeding duration. Therefore, regarding the significance of instructing mothers and its effects on breastfeeding efficiency, this research was conducted to investigate the effects of pregnancy care instruction at home on the breastfeeding efficiency of first-time pregnant women.

Materials and Methods: In this clinical proficiency research, 65 first-time pregnant women, in their last 3 months of pregnancy, who referred to the clinics related to Shiraz medical school, were studied in 2 groups of treatment and control. The research instruments were 2 questionnaires, one of which contained demographic characteristics and the other one was Breastfeeding SelfEfficacy Questionnaire developed by Dennis. Six sessions of educational programs were conducted for the treatment group at home ( 3 sessions in the last 3 months of pregnancy and 3 sessions in the first, second, and sixth weeks after delivery). Meanwhile, a questionnaire on breast-feeding self-efficacy was filled out and analyzed in both groups.

Results: Both groups were the same in demographic variables. Variance analysis test showed that there was a significant difference in the mean scores of breastfeeding self-efficacy between the 2 groups $(P<0.001)$.

Conclusion: Instruction of pregnancy care (at home), focusing on feeding by mother's milk, is effective in increasing the efficacy of mother's breast-feeding.

Keywords: Instruction at home, Prenatal care, Breastfeeding self-efficiency, First-time pregnant women
\end{abstract}

\section{Introduction}

Mother's milk is a complex biologic liquid and the ideal meal for babies. It could provide, both qualitatively and quantitatively, the most nutritious balance for babies $(1,2)$. Therefore, just being fed by mother's milk is strongly recommended for the first 6 months of babies' life until she is 2 years old. But we must take this important fact into consideration that being fed by mother's milk must be along with supplementary meals (3).

Exclusive feeding by mother's milk could surely bring the perfect nutrition for an infant and can provide the baby with the benefits of colostrum and mother's milk (4). Studies have shown that the infants fed by mother's milk would, at a lower level, suffer from digestive and respiratory diseases, infection of the tympanum, and other diseases (5).

The worldwide rate of exclusive breast-feeding in 4-month-old infants is $56.8 \%$ and in 6-month infants it is $27.7 \%$. This amount, in rural regions in Iran, is $58 \%$ in 4-month-old infants and it is $29 \%$ in 6-month-old ones.
This rate, in urban areas of Iran, is 56\%in 4-month-old infants and it is $27 \%$ in 6-month-old ones (6). Although universal measures have been taken to encourage people to choose mother's milk and prolong the period of breastfeeding, still critical problems have been reported by mothers, indicating that after their delivery, they had to stop breastfeeding their infants (7). Despite the benefits of feeding infants by mother's milk until the first 6 months after their babies' birth, nowadays, we witness the decrease of breastfeeding in the world which has been one of the most serious challenges to the public health (8).

Self-efficiency in breastfeeding is a very salient point in predicting the duration of breastfeeding. It could also contribute to identify the mothers who immediately quit the period of breastfeeding. Self-efficiency in breastfeeding is also regarded as a comprehensive potency of the mother in feeding her infant(s) and is a valuable framework which could predict the mother's breastfeeding behavior, showing a mother's self-confidence and her ability in feeding her child (9). 
According to Hasanpoor et al who studied the extent of breastfeeding self-efficacy in the last month of pregnancy, only $2.5 \%$ of pregnant women had a high level of selfefficiency. Therefore, employing proper strategies is necessary in order to increase the breastfeeding selfefficacy in women (10).

According to Bandura's theory, breastfeeding self-efficacy is influenced by 4 informational resources as follows: former breast-feeding experience, observing successful breastfeeding women, influence of one's physiological and/or affective states like fatigue, stress, and anxiety and being encouraged by influential people like friends, family and former consultants (11). Bandura believes that the extent of mother's breastfeeding self-efficacy could be increased through developing instructional strategies in acquiring skills and needed knowledge $(12,13)$.

Regarding the fact that breastfeeding self-efficacy of mothers is influenced by their past breastfeeding experiences, the primigravida women, due to the lack of experience, encounter some problems in exclusively breastfeeding their infants (14).

Presenting instructional packages in a short period of time after childbirth (as it is seen in most child-friendly hospitals ) is just some information and naked facts to the mothers in order to encourage them to breastfeed their baby temporality. This strategy is not functional due to the improper condition of mothers after suffering pains and tiredness of their delivery.

This indicates the significance of removing the limitations on time and place, and also the condition of a woman being instructed in choosing an effective educational method must be considered (15). Overall, due to the decrease of feeding by mother's milk in France in recent years, it is a virtue to develop proper strategies for increasing the breastfeeding self-efficacy of mothers (primigravidas in particular); and it is also regarded necessary for health care providers to pay full attention to this issue for improving the process of breast feeding $(16,17)$.

Several studies have proven the positive roles of instructional plans in improving the results of breastfeeding. However, unfortunately, implementing these plans at home during pregnancy and continuing it for 6 weeks after childbirth have not properly been effective in breastfeeding self-efficacy.

Thus, the researcher decided to investigate the effects of pregnancy care on breastfeeding self-efficacy of first-time pregnant women. The results of this study would help to recommend more functional methods for improving the results of breastfeeding.

\section{Materials and Methods}

The present study was an interventional study; the participants were the first-time pregnant mothers who had referred to clinics affiliated to Shiraz medical college in the last 3 months of their pregnancy. The inclusion criteria of the study were (a) living in Shiraz during the study, (b) passing more than 6 months of their pregnancy, (c) being literate (minimum ability to write and read), and (d) not taking part in former educational sessions.

The main goal in this study was to compare and evaluate the mean score of breastfeeding self-efficacy in both treatment and control groups in which the mean difference $\left(\mu_{1}-\mu_{2}\right)$ was 1.5 , standard deviation was 7 , power (1- $\beta$ ) was $80 \%$ and significance level was 0.05 ; and about 30 individuals were measured in each group. Considering the possibility of $20 \%$ falling, the population changed to 35 individuals $(\mathrm{n}=70)$.

Thus, in order to achieve the goals of the research, the researcher (considering the ethical issues, getting recommendation letter from the security of Fatima-Zahra Nursing and Midwifery College, and referring to Enghelab and Val-Fajr clinics in order to obtain permission) used multi-stage random sampling which was a mixture of stratified and random sampling.

First step: Both Enghelab and Val-Fajr clinics were sampled by stratified sampling method.

Second step: $20 \%$ of the clinics related to Enghelab and ValFajr clinic centers were selected randomly. (It means that clinics were selected out of 40 clinics related to Enghelab and 2 clinics were selected out of 10 clinics related to ValFajr clinic center.

Third step: 70 women were randomly selected from all these 10 clinics ( 7 women for each clinic).

Fourth step: Then, they were allocated to treatment and control groups. Thirty-five women decreased to 33 in the treatment group and 35 decreased to 32 in the control group.

After sampling and explaining the goals and the benefits of this research to the women, the consent form and the questionnaire of demographic characteristics were filled out by individuals. Then, research units were divided into 2 groups of control and treatment and their addresses and phone numbers were received.

Then, 3 educational sessions were held for the treatment group ( 3 sessions in 3 weeks) in their house and also an educational pamphlet was given to them. These educational sessions were about prenatal care plans including pregnancy nutrition, common problems in the last 3 months of pregnancy, blood pressure and weight checkup, timely referral to clinics for receiving pregnancy care, breast care plans, and breastfeeding instructions and advice.

Then, the researcher visited the treatment group in their houses in order to do the research and instruct them after their childbirth according to the goals. These instructions are as follows:

(a) Breast care, (b) infant umbilical care, $(c)$ psychological support from mothers, and $(d)$ infant's illness symptoms

Then, the questionnaire on breast-feeding self-efficacy was filled out in both treatment and control groups 3 weeks after childbirth. The first questionnaire was about "demographic information" including questions about 
age, job, education, and some questions about pregnancy (weeks of pregnancy, abortion experience etc).

Questionnaire Validity and Reliability

Breastfeeding self-efficacy Questionnaire developed by Dennis includes 14 questions in 5-point Likert scale and according to Bandura's self-efficacy theory, is designed in the form of positive statements. The range of scores is considered from 1 (indicating "never or not sure at all") to 5 (indicating "always or pretty sure") for each response. The Range of breastfeeding self-efficacy scores respectively included a minimum of 14 to a maximum of 70. The scores 14-32 showed weak self-efficacy, 33-51 showed average self-efficacy and 52-70 showed a good efficacy in the mothers. The reliability of the questionnaire was measured $(r=0.78)$ and was confirmed in a study conducted by Karbandi et al (18).

Data analysis was done using chi-squared test, Fisher exact test, independent $t$ test, frequency-based variance analysis, one-way variance analysis (ANOVA), Pearson correlation coefficient. SPSS software version 19.0 was used for analysis of data.

\section{Results}

Demographic characteristics of the research samples showed that $65.6 \%$ of the mothers in the control group and $84.8 \%$ in the treatment group had a natural childbirth (delivery), indicating the fact that the percentage of natural childbirth in the treatment group was higher than that of the control group.

$81.2 \%$ of the mothers in the control group and $84.8 \%$ of them in the treatment group were between 20 to 30 years old.

$54.6 \%$ of the mothers in the treatment group and $78.1 \%$ in the control group had a diploma and a BA degree. Most of the pregnant women in both groups were

housewives, $81.3 \%$ in control group and $90.9 \%$ in the treatment group.

Both control and treatment groups were compared using chi-squared test and Fisher exact test. The result of independent $t$ test showed no significant difference in the quantity and quality of demographic characteristics of individuals $(P>0.05)$ and as a result, both groups were the same in terms of qualitative and quantitative demographic features (Table 1).

Table 2 shows the comparison between the mean scores of breastfeeding self-efficacy in the control and treatment groups. There is a significant difference between control and treatment groups in the mothers' in terms of breastfeeding self-efficacy $(P<0.001)$ (Figure 1$)$.

\section{Discussion}

According to the results of chi-squared test, Fisher test and independent $t$ test, there was a significant difference in the demographic and clinical variables $(P<0.05)$; therefore, it can definitely be concluded that the changes in breastfeeding self-efficacy in first-time pregnant (primigravida) women were the result of the treatments that have been conducted during the research.

Results of this research indicated an increase in breastfeeding self-efficacy in primigravida women 6 weeks after the treatment was finished.

This indicates the effects of treatment on breast feeding self-efficacy of primigravida in the treatment

Table 1. Comparison of the Groups in Terms of Demographic Qualitative Features

\begin{tabular}{|c|c|c|c|c|c|c|c|}
\hline \multirow{3}{*}{ Variable } & \multicolumn{4}{|c|}{ Group } & & & \multirow{3}{*}{$P$ Value } \\
\hline & \multicolumn{2}{|c|}{ Test $(n=33)$} & \multicolumn{2}{|c|}{ Control $(n=32)$} & \multicolumn{2}{|c|}{ Total $(n=65)$} & \\
\hline & No. & $\%$ & No. & $\%$ & No. & $\%$ & \\
\hline \multicolumn{8}{|l|}{ Baby's sex } \\
\hline Girl & 20 & 62.2 & 20 & 60.6 & 40 & 61.5 & \multirow{2}{*}{0.89} \\
\hline Boy & 13 & 39.4 & 12 & 37.5 & 25 & 38.5 & \\
\hline \multicolumn{8}{|l|}{ Type of confinement } \\
\hline Natural & 28 & 84.8 & 21 & 65.6 & 49 & 75.4 & \multirow{2}{*}{0.06} \\
\hline Caesarean section & 5 & 15.2 & 11 & 34.4 & 16 & 26.6 & \\
\hline \multicolumn{8}{|l|}{ Age } \\
\hline Before 20 years & 4 & 8.13 & 9 & 6.15 & 5 & 1.12 & \multirow{4}{*}{0.87} \\
\hline $20-25$ & 16 & 50 & 16 & 48.5 & 32 & 49.2 & \\
\hline $25-30$ & 12 & 36.4 & 10 & 31.3 & 22 & 33.8 & \\
\hline After 30 years & 1.3 & 2 & 3 & 1 & 1.31 & 1 & \\
\hline \multicolumn{8}{|l|}{ Education } \\
\hline High school diploma & 12 & 36.4 & 7 & 21.9 & 12 & 29.2 & \multirow{4}{*}{0.91} \\
\hline Diploma & 12 & 36.4 & 12 & 37.5 & 24 & 36.9 & \\
\hline Baccalaureate & 6 & 18.2 & 13 & 40.6 & 19 & 29.2 & \\
\hline Higher degrees & 3 & 9.1 & 0 & 0 & 3 & 4.6 & \\
\hline \multicolumn{8}{|l|}{ Job } \\
\hline Clerk & 3 & 9.1 & 3 & 9.4 & 6 & 9.2 & \multirow{3}{*}{0.77} \\
\hline Housewife & 30 & 90.9 & 26 & 81.3 & 56 & 86.2 & \\
\hline Others & 0 & 0 & 3 & 9.4 & 3 & 4.6 & \\
\hline
\end{tabular}


Table 2. Control and Treatment Groups' Breastfeeding Self-efficacy

\begin{tabular}{llccc}
\hline Group & No. of Weeks After Delivery & Mean & SD & $\boldsymbol{P}$ \\
\hline \multirow{2}{*}{ Treatment } & First week after delivery & 44.97 & 5.79 & 0.000 \\
& Second week after delivery & 51.54 & 2.96 & 0.000 \\
& Sixth week after delivery & 58.24 & 10.60 & 0.000 \\
\hline \multirow{2}{*}{ Control } & First week after delivery & 38.41 & 8.22 & 0.000 \\
& Second week after delivery & 40.75 & 7.03 & 0.000 \\
& Sixth week after delivery & 46.44 & 4.61 & 0.000 \\
\hline
\end{tabular}

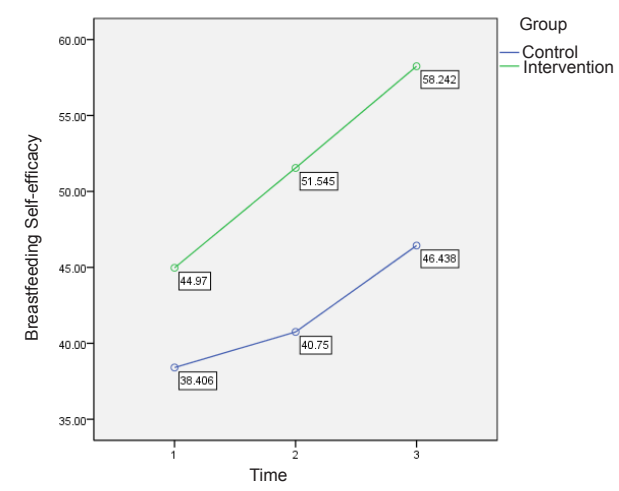

Figure 1. Changes in the Average of Breastfeeding Self-efficacy Scores in First, Second, Sixth Weeks After delivery in both groups.

group. Therefore, there were no significant changes in breastfeeding of the control group. It is interesting to say that the small increase of the scores of the breastfeeding self-efficacy in control group could be related to the experiences that have been achieved by their own or their relative compatibility with the existing condition.

Sakkaki et al in a study showed that plans for home visits positively affected the mothers' breast feeding self-efficacy immediately after they are discharged from the hospital. These findings are consistent with the current research (19).

However, Kellams et al showed that video education on pregnancy care did not significantly affect the breastfeeding self-efficacy of mothers after the infant's birth. This study showed that video instructions are not enough; however, there is a need for trying other aspects of the education of pregnant women. It is worth mentioning that more attention should be paid to mothers' condition and their limitations regarding time and place of their education (20).

In this study, in order to improve the level of primigravida women's self-efficacy, there have been numerous educational sessions based on age, education, comprehension, their need for pamphlets and allotting more time to speech, visual methods, performances, talk show, cooperative life, and questions and answers for mothers and their assistants at home.

The current research showed that pregnancy cares at home are effective in breastfeeding self-efficacy of primigravida women; this result is in line with the study done by Taheri et al (21). However, results of a study by Azhari et al, which was done on the comparison of the effects of 2 educational methods (with and without the instructor's intervention), is contrary to breast feeding self-efficacy of primigravida women (22).

In the research by Azhari et al (22), breast feeding selfefficacy in the treatment group without direct intervention was higher than the treatment group with direct intervention. It is assumed that the difference between the results is due to the fact that he simply utilized pictures of breast feeding as an intervention, while we used home education in the current study.

Ghodsbin et al investigated the effects of home visits (in the first 6 weeks after childbirth) on the quality of primigravida women's life, they showed that home visit is a very proper educational method for improving the quality of primigravida women's life (23).

However, Doyle et al in a study aimed at investigating the effects of the home-based educational intervention on the pregnancy outcomes in Dublin; They showed that home visit plans are not effective. It is due to the fact that, in this

Table 3. Comparison of the Mother's Demographic Features With Their Mean Score of Breastfeeding Self-efficacy in Both Groups

\begin{tabular}{|c|c|c|c|c|c|c|c|}
\hline \multirow{2}{*}{\multicolumn{2}{|c|}{ Demographic Variable }} & \multicolumn{2}{|c|}{ Test Group } & \multicolumn{2}{|c|}{ Control Group } & \multirow{2}{*}{$\begin{array}{c}P \text { Value of Test } \\
\text { Group }\end{array}$} & \multirow{2}{*}{$\begin{array}{c}P \text { Value of Control } \\
\text { Group }\end{array}$} \\
\hline & & Average & Diversion Factor & Average & Diversion Factor & & \\
\hline \multirow{2}{*}{ Confinement } & Natural & 1.51 & 9.5 & 1.40 & 08.7 & \multirow{2}{*}{0.20} & \multirow{2}{*}{0.03} \\
\hline & Caesarean section & 54 & 2.7 & 1.45 & $1 / 2$ & & \\
\hline \multirow{4}{*}{ Age } & Before 20 years & 3.48 & $1 / 2$ & 2.34 & 2.3 & \multirow{4}{*}{0.71} & \multirow{4}{*}{0.01} \\
\hline & $20-24$ & 7.51 & 3.6 & 4.42 & 5.5 & & \\
\hline & $25-30$ & 4.52 & 3.7 & 1.45 & 2.6 & & \\
\hline & After 30 years & 6.52 & - & 50 & - & & \\
\hline \multirow{4}{*}{ Education } & High school diploma & 1.50 & 9.3 & 4.38 & 8.7 & \multirow{4}{*}{0.28} & \multirow{4}{*}{0.07} \\
\hline & Diploma & 3.52 & 57 & 1.42 & 8.4 & & \\
\hline & Baccalaureate & 7.50 & 2.3 & 4.43 & 7 & & \\
\hline & Higher degrees & 1.56 & 5.8 & - & - & & \\
\hline \multirow{3}{*}{ Mother's job } & Clerk & 7.54 & 9.9 & 4.43 & 9.13 & \multirow{3}{*}{0.99} & \multirow{3}{*}{0.42} \\
\hline & Housewife & 7.53 & 7.5 & 9.40 & 6.5 & & \\
\hline & Free & - & - & 3.48 & $1 / 2$ & & \\
\hline \multirow{2}{*}{$\begin{array}{l}\text { History of } \\
\text { abortion }\end{array}$} & Yes & 8.53 & 2.7 & 5.42 & 5.5 & \multirow{2}{*}{0.22} & \multirow{2}{*}{0.49} \\
\hline & No & 5.51 & 9.5 & 6.41 & 9.6 & & \\
\hline
\end{tabular}


study, there was no focus on stress factors, psychological condition of mothers, and effects of improper conditions (24).

In the present study, the investigation of the relationship between demographic characteristics and breast-feeding self-efficacy showed that, except for age and type of childbirth in the control group, other demographic characteristics did not have a significant relationship with breast-feeding self-efficacy.

Numerous studies have shown that mothers' education and other basic factors are related to breastfeeding self-efficacy of mothers; however, in the present study, there was no significant relationship between the above-mentioned factors and breast feeding self-efficacy of mothers. These results are compatible with the studies by Bastani et al (25), Blyth et al (26), and Dennis (27); however, the results are not consistent with those of the studies conducted by Merker (28) and Varaei et al (29). It could be assumed that in the present study, the participants were primigravida women who were approximately at the same age, and had a BA or a diploma degree and more than $85 \%$ of them were housewives. Therefore, we did not find a significant relationship between these mentioned variables.

Generally, pregnancy and post-delivery cares in primigravida women seem to be necessary, because they lack the experience and enough information about breastfeeding. This study showed that providing instruction at home that is compatible with mothers' need and condition would improve breastfeeding self-efficacy in primigravida women.

\section{Conflict of Interests}

Authors declare that they have no conflict of interests.

\section{Ethical Issues}

The ethical issues considered in this study included obtaining informed consent from the participants in research, the authorization of health centers of Valfajr and Enghelab clinics, confidentiality of information collected from individuals, providing training protocol for the control group after completion of the research. This study was registered at the Iranian registry of clinical trials website (identifier: IRCT201406107531N10; http:irct.ir).

\section{Financial Support}

This study was founded by Shiraz University of Medical Sciences.

\section{Acknowledgements}

The authors would like to thank Shiraz University of Medical Sciences, Shiraz, Iran and also Center for Development of Clinical Research of Namazee.

\section{References}

1. Kliegman RM, Stanton B, Geme JS, Schor NF, Behrman RE. Nelson Textbook of Pediatrics. New York: Elsevier; 2015.
2. Schanler RJ, Krebs N, Mass S. Breastfeeding Handbook for Physicians. American Academy of Pediatrics; 2013.

3. Breastfeeding and the use of human milk. Pediatrics. 2012;129(3):e827-841. doi:10.1542/peds.2011-3552

4. Maury S. Breastfeeding information \& guideline a manual for breastfeeding support in pediatric \& neonatal units. Trans. by Saadvandian S, Tahery M. Mashhad: Sokhan Gostar; 2007:22-70. (In Persian)

5. Gartner LM, Morton J, Lawrence RA, et al. Breastfeeding and the use of human milk. Pediatrics. 2005;115(2):496506. doi:10.1542/peds.2004-2491

6. Olang B, Farivar K, Heidarzadeh A, Strandvik B, Yngve A. Breastfeeding in Iran: prevalence, duration and current recommendations. Int Breastfeed J. 2009;4:8. doi:10.1186/1746-4358-4-8

7. Akbari M, Zarenejhad A. Broadcasting in health in Islamic Republic of Iran. Tehran: Rah Tarahan Farda Pub; 2006.

8. Aghdas K, Talat K, Sepideh B. Effect of immediate and continuous mother-infant skin-to-skin contact on breastfeeding self-efficacy of primiparous women: a randomised control trial. Women Birth. 2014;27(1):37-40. doi:10.1016/j.wombi.2013.09.004

9. Bowles BC. Promoting Breastfeeding Self-Efficacy: Fear Appeals in Breastfeeding Management. Clinical Lactation. 2011;2(1):11-14. doi:10.1891/215805311807011782

10. Hasanpoor S, Bani S, Ansari S, Ebrahimi H. Measuring breastfeeding self-efficacy among pregnant women referred to health centers of Ahvaz. Nursing Midwifery Journal. 2010;5(19):47-53.

11. Peyman N. Modifying and evaluating of Steps of Behavior Change (SBC) model integrated with Self efficacy theory in order to decrease unwanted preg-nancy [dissertation]. Tehran: Department of Health Education, School of Medical Sciences, Tarbiat Modares University; 2007.

12. Weimers L, Svensson K, Dumas L, Naver L, Wahlberg V. Hands-on approach during breastfeeding support in a neonatal intensive care unit: a qualitative study of Swedish mothers' experiences. Int Breastfeed J. 2006;1:20. doi:10.1186/1746-4358-1-20

13. McCarter-Spaulding DE, Kearney MH. Parenting selfefficacy and perception of insufficient breast milk. J Obstet Gynecol Neonatal Nurs. 2001;30(5):515-522.

14. Breastfeeding: Best practice guidelines for nurses. The Registered Nurses' Association of Ontario (RNAO) website. http://www.rnao.org. Published 2003..

15. Joffe H, Cohen LS, Harlow BL. Impact of oral contraceptive pill use on premenstrual mood: predictors of improvement and deterioration. Am J Obstet Gynecol. 2003;189(6):15231530 .

16. Sharon K. The effects of Maternal Psychological Factors on Maternal Competence for Infant Feeding [dissertation ]. Nashville, USA: Vanderbilt University; 2008.

17. PajaresF. Self-EfficacyBeliefs in Academic Settings. RevEduc Res. 1996;66(4):543-578. doi:10.3102/00346543066004543

18. Karbandi S, Hosseini SM, Masoudi R, Mamori GA. The effect of relaxation training on breastfeeding self-efficacy of mothers with preterm infants: A randomized clinical trial. Journal of Clinical Nursing and Midwifery. 2014;4(3):3745.

19. Sakkaky M, Danesh Kojuri M, Khairkhah M, Hosseini AF. The Effect of Home Visit after Cesarean Delivery on Exclusive Breastfeeding in Neonatal Period. Iran J Nur. 2010;23(64):72-80. [Persian]. 
20. Kellams AL, Gurka KK, Hornsby PP, et al. The Impact of a Prenatal Education Video on Rates of Breastfeeding Initiation and Exclusivity during the Newborn Hospital Stay in a Low-income Population. J Hum Lact. 2016;32(1):152159. doi:10.1177/0890334415599402

21. Taheri Z, Mazaheri MA, Khorsandi M, Hassanzadeh A, Amiri M. Effect of Educational Intervention on Self-efficacy for Choosing Delivery Method among Pregnant Women in 2013. Int J Prev Med. 2014;5(10):1247-1254.

22. Azhari S, Baghany R, Akhlaghi F, Ebrahim Zadeh S, Salehi Federdi J. Comparing the effects of hands-on and handsoff breastfeeding methods on self-efficacy in primiparous mothers. Journal of Sabzevar University Medical Sciences. 2011;17(4):248-255.

23. Ghodsbin F, Yazdani K, Jahanbin I, Keshavarzi S. The effect of education on health-promoting behaviors at the first six weeks post-delivery on the quality of life of primiparous women. Armaghane Danesh. 2012;17(4):279288. [Persian].

24. Doyle O, McGlanaghy E, Palamaro-Munsell E, McAuliffe
FM. Home based educational intervention to improve perinatal outcomes for a disadvantaged community: a randomised control trial. Eur J Obstet Gynecol Reprod Biol. 2014;180:162-167. doi:10.1016/j.ejogrb.2014.06.006

25. Bastani F, Rahmatnejad L, Jahdi F, Haghani H. Breastfeeding Self Efficacy and Perceived Stress in Primiparous Mothers. Iran J Nurs. 2008;21(54):9-24. [Persian].

26. Blyth R, Creedy DK, Dennis CL, Moyle W, Pratt J, De Vries SM. Effect of maternal confidence on breastfeeding duration: an application of breastfeeding self-efficacy theory. Birth. 2002;29(4):278-284.

27. Dennis CL. Identifying predictors of breastfeeding selfefficacy in the immediate postpartum period. Res Nurs Health. 2006;29(4):256-268. doi:10.1002/nur.20140

28. Mercer RT. A theoretical framework for studying factors that impact on the maternal role. Nurs Res. 1981;30(2):7377.

29. Varaei S, Mehrdad N, Bahrani N. The Relationship between Self-efficacy and Breastfeeding, Tehran, Iran. Hayat. 2009;15(3):31-38.

Copyright (C) 2018 The Author (s); This is an open-access article distributed under the terms of the Creative Commons Attribution License (http://creativecommons.org/licenses/by/4.0), which permits unrestricted use, distribution, and reproduction in any medium, provided the original work is properly cited. 